$\pm 1.09 \%$, of which $9.79 \pm 1.05 \%$ were admitted to surrender, and the special medical group determined $1.49 \pm 0.43 \%$ of children and adolescents (all $\mathrm{p}<0.001$ ).

\section{P316 GENERAL DISABILITY OF PATIENTS OF THE CITY CHILDREN'S POLYCLINIC OF THE SUBARCTIC TERRITORY}

\begin{abstract}
${ }^{1,2}{ }^{2}$ Konstantin Shapovalov*, ${ }^{*}$ 'Larisa Shapovalova, ${ }^{2}$ Tatiana Yastrebtseva, ${ }^{2}$ Marina Gorbitskaya, ${ }^{2}$ Natalya Semyannikova, ${ }^{2}$ Ksenia Avtushina. ${ }^{1}$ State Education Agency of Additional Professional Education of Republic of Komi 'Komi Republican Institute for Development of Education', Syktyvkar, Russian Federation; ${ }^{2}$ State Budget Agency of Health of the Republic of Komi ' Syktykar children's clinic [3]', Syktyvkar, Russian Federation
\end{abstract}

10.1136/archdischild-2019-epa.665

Childhood disability is a major marker of health status of the child population and prospects for its social well-being.

The analysis of diseases that caused the occurrence of disability in 710 disabled children was conducted. State Budget Agency of Health of Republic of Komi 'Syktyvkar children`s clinic 53', who were disabled in 2016-2018. Control group consisted of 901 patients of 'SCC $\square 3$ ' who were disabled in 2011-2015.

Determined the ranking of diseases that caused the emergence of disability in children with disabilities, their structure and frequency per 10,000 contingent patients of clinics

When working on material used methodological approaches: systemic, integrated, integration, functional, dynamic, process, regulatory, quantitative, administrative and situational. Used methods: historical, analytical and comparison. The following techniques were used: grouping, absolute and relative values, average values, detailing and generalization. The significance of differences in quantitative characteristics between groups with a normal distribution of quantitative variables was calculated using Student's t-criteria for independent samples.

The formed indicators of the general disability of the contingent of patients of the urban children's clinic of the regional center of the subarctic territory is a statistical tool of everyday use for the objectification of the rehabilitation process, their comparative evaluation and determination of the strength and means of a medical institution for its successful maintenance.

For period from 2011-2018. total (widespread) disability in 'SCC 03 ' increased in absolute terms from 166 to 261 people, that is, 1.57 times and, correspondingly, with a growth rate of $157.23 \%$. The frequency of primary disability increased 1.34 times from 118.69 per 10,000 patients to 159.92, while the growth rate was $134.73 \%$. With outpacing growth of primary disability over general trend of further growth in number of disabled children will increase.

Based on the calculations in 2019, no less than 86-90 disabled children are expected, who will have VI G00-G99 Diseases of nervous system $(36.33-35.44 \%, \%$ in overall structure and frequency 57.59) as leading pathology. -52.41 per 10,000 patients). As a result of examinations, 55-53 children with XVII Congenital anomalies, chromosomal disorders Q00-Q99 (23.46-22.25\%, frequency - 33.70-32.09) will be identified as disabled; 31-26 children with IV Endocrine Disorders, eating disorders and metabolic disorders E00-E90 (11.88-10.85\%, frequency 18.99-15.64); II neoplasms C00-D48 (10.34$9.86 \%$, frequency 16.54-14.22); VIII Diseases of the ear and mastoid H60-H95 (9.30-9.00\%, frequency 12.12-11.64); 9-8 children with XIII Diseases of the musculoskeletal system and connective tissue M00-M99 (4.28-3.83\%, frequency - 6.135.58); VII. Diseases of the eye and adnexa H00-H59 (3.60$3.45 \%$, frequency $5.51-4.69$ )

\section{P317 THE STUDY OF AVAILABLE AND PROMISING METHODS OF DIAGNOSIS, CORRECTION AND TREATMENT OF FETAL OVARIAN TUMORS (CYSTS) IN THE FETUS, WITH MAXIMUM PRESERVATION OF THE FUNCTION OF THE REPRODUCTIVE SYSTEM. THE STUDY WAS FORMED BY THE LEADING DOCTORS OF THE PERINATAL CENTER OF THE ST. PETERSBURG STATE PEDIATRIC MEDICAL UNIVERSITY}

Anna Taits*, Dmitriy Ivanov, Anna Malisheva, Ivan Errshov. The Perinatal Center of the St Petersburg State Pediatric Medical University, St. Petersburg, Russian Federation

\subsection{6/archdischild-2019-epa.666}

The most frequent complication is the twisting of the legs of an ovarian cyst in $61 \%$ cases, intestinal obstruction in 3\%. Twisting an ovarian cyst can spontaneously regress, but it can also cause embedding the appendages themselves and their migration to different parts of the abdominal cavity and cause sudden death of the newborn. Indications for surgical treatment are: the size of a cyst is more than $4 \mathrm{~cm}$, signs of torsion, a migrating cyst.

Materials and methods In our study, there were 20 girls born on the term from 26 to 41 weeks of gestation, in 7 cases through cesarean section, and in 13 cases through the birth canal. 15 girls from the group of newborns diagnosed with prenatal from 30 to 36 weeks of pregnancy were hospitalized in the department of pathology of newborns and premature babies in the period from 1 to 5 days of life and 3 girls of infancy in 1-1.5-2 months of life, due to the fact that the diagnosis is made in a month of life. The examination of the girls included anamnesis, general clinical studies, an ultrasound examination of the pelvic organs and the abdominal cavity was performed. In 11 cases out of 20 additional multispiral computed tomography was required, as well as histological examination of the surgical material. Surgical treatment was performed on all girls with laparoscopic transumbulial minilaparotomy. All interventions were performed as far as possible with maximum preservation of ovarian tissue. In 12 girls, adnexectomy was performed due to necrotic changes of the appendages as a result of torsion of $45 \%$ and in combination with adhesive disease 15\%. Ovariocytectomy was performed in 6 cases. And in 2 cases enterokistoma was detected. According to the morphological assessment of ovarian lesions in newborns, in most cases there are simple follicular ovarian cysts with hemorrhages, calcification and necrosis during torsion.

Conclusions Particular attention should be paid to quality prenatal diagnosis with a detailed assessment of all criteria for simple and complex ovarian cysts and the question of the possible use of fetal surgery, which will facilitate the timely adoption of measures and prevent the occurrence of complications with subsequent loss of appendages. An obstetrician-gynecologist should be involved at all stages of the management and treatment of this category of patients from the moment of prenatal diagnosis. Surgical treatment of these patients should be carried out in specialized hospitals using high-tech methods. 